\title{
Drug use and the severity of a traffic accident
}

\author{
B.E. Smink ${ }^{\mathrm{a}, *}$, B. Ruiter ${ }^{\mathrm{a}}$, K.J. Lusthof ${ }^{\mathrm{a}}$, J.J. de Gier ${ }^{\mathrm{c}, \mathrm{d}}$, \\ D.R.A. Uges ${ }^{\mathrm{b}}$, A.C.G. Egberts ${ }^{\mathrm{d}}$ \\ a Netherlands Forensic Institute, Department of Toxicology, P.O. Box 24044, 2490 AA The Hague, \\ The Netherlands \\ ${ }^{\mathrm{b}}$ State University and University Hospital Groningen, Department of Pharmacy, Toxicology and Forensic Medicine, \\ P.O. Box 30001, 9700 RB Groningen, The Netherlands \\ ${ }^{c}$ University of Groningen, Groningen Research Institute for Pharmacy, Department of Pharmacotherapy and Pharmaceutical Care, \\ A. Deusinglaan 2, 9713 AW Groningen, The Netherlands \\ ${ }^{\mathrm{d}}$ Utrecht Institute for Pharmaceutical Sciences, Department of Pharmacoepidemiology and Pharmacotherapy, \\ P.O. Box 80082, 3508 TB Utrecht, The Netherlands
}

Received 22 January 2004; received in revised form 26 November 2004; accepted 13 December 2004

\begin{abstract}
Several studies have showed that driving under the influence of alcohol and/or certain illicit or medicinal drugs increases the risk of a (severe) crash. Data with respect to the question whether this also leads to a more severe accident are sparse. This study examines the relationship between the use of alcohol, illicit drugs and/or medicinal drugs and the severity of an accident within a group of drivers that were involved in a crash in The Netherlands. Blood samples of 993 drivers, collected in the period from October 1998 through September 1999, were linked to accident characteristics as available from the National Transport Research Centre. The outcome measure was the severity of the accident. An accident was considered severe when the accident had resulted in hospital admission or death. All the blood samples obtained after the accident were screened for the presence of alcohol, illicit drugs (opiates, amphetamines and amphetamine-like substances, cocaine and metabolites, methadone, cannabinoids) and medicinal drugs (benzodiazepines, barbiturates and tricyclic antidepressants). The strength of the associations between exposure to the different classes of alcohol/drugs/medicines and the severity of the accident was evaluated using logistic regression analysis and were expressed as odds ratios (OR), adjusted for age, gender, time of the day, day of the week and urban area. The most frequently detected drugs were cannabinoids, benzodiazepines and cocaine. Our results showed no clear association between the use of alcohol, illicit drug and/or medicinal drug use and the severity of the accident. Given the process of obtaining blood samples from drivers involved in accidents and the retrospective nature of the study, we cannot rule out the occurrence of selection bias. Therefore, our findings need further confirmation.
\end{abstract}

(C) 2004 Elsevier Ltd. All rights reserved.

Keywords: Alcohol; Drugs; Medicines; Traffic accident; Severity

\section{Introduction}

The relation between alcohol consumption and the risk of a traffic accident has been extensively studied; the accident risk clearly increases with the increasing blood alcohol concentration (Borkenstein et al., 1974; Hurst et al., 1994).

\footnotetext{
* Corresponding author. Tel.: +31 7088866 11; fax: +317088865 52 .

E-mail address: b.smink@nfi.minjus.nl (B.E. Smink).
}

Several studies have also shown that the use of psychoactive substances other than alcohol is associated with an increased risk of accidents (Barbone et al., 1998; Honkanen et al., 1980; Neutel, 1998; Movig et al., 2004). For most of these substances, however, no clear concentration-effect relationship between the concentration of the parent substance and impairment or accident risk has been established, although some studies do indicate that it exists. Harder and Reitbrock (1997) described the relationship between $\Delta-9$ tetrahydrocannabiol concentrations and psychotropic effects. 
Barbone et al. (1998) found a dose-response relation for benzodiazepines and road traffic accidents. The study of Bramness et al. (2002) indicates a concentration-related effect of benzodiazepines on driving impairment.

However, some results are conflicting and many unresolved questions remain. Complicating factors in determining the influence of drug use on the driving performance include the variable doses of illicit drugs with an unknown pattern of use, interindividual variation in response to a given dose and tolerance. In case of medicinal drug use, the availability of exposure data based on the medication records may help to control for bias by previous exposure to drugs. In addition, practical and ethical reasons hamper the optimal design for epidemiological studies into the relation between drug use in daily traffic and accidents. The most frequently applied design is the case-control study in which drug use among crash involved drivers is compared to the drug use among a control group of drivers not involved in a crash. In general, the major outcome measure of those studies is the relative risk (expressed as odds ratios (OR)) of involvement in a crash for drugged drivers versus not drugged drivers (Robertson and Drummer, 1994).

Another remaining question is for persons who have been involved in a crash, whether drug use has led to more severe outcomes. In relation to road safety, it is not only important to prevent the accidents but also to gain insight into the factors governing morbidity and mortality. For example, the use of seat belts in relation to car crash injury has been described in several studies (Valent et al., 2002; Ichikawa et al., 2002; Kim and Kim, 2003). Kim et al. (1995) studied the relation among personal and behavioral aspects, types of crashes and levels of injuries. To our knowledge, no information is available about the association between the use of different classes of drugs and the level of injury after the accident has taken place. The objective of our study is to evaluate the relationship between alcohol/drug use and the severity of the accident in those drivers who are involved in a crash.

\section{Methods}

\subsection{Setting}

In The Netherlands, Article 8 of the Road Traffic Act states that it is forbidden to drive a vehicle under the influence of substances that the driver ought to know that these affects the driving proficiency. In cases of conspicuous deviant driving behavior at regular roadside controls or after a traffic accident, blood or urine samples can be taken for analysis of alcohol and drugs affecting driving performance. These samples are sent to one central laboratory, the Netherlands Forensic Institute (NFI) by each of the 25 regional police forces of the Dutch police.

For developing traffic safety policies, data from all road crashes that occurred in The Netherlands are collected by the National Transport Research Centre (Adviesdienst Verkeer en Vervoer) in Heerlen. From each accident, the location, road conditions, characteristics of the driver, severity of the injury, day of the week and time of the day are known.

\subsection{Study population}

In the period from October 1998 through September 1999, blood samples of 1347 drivers involved in crashes were collected in The Netherlands. Data have been made anonymous. Blood samples were linked to the accident records of the Transport Research Centre on the basis of date of birth of the driver, time of blood sampling and the district. The total number of traffic accidents registered by the Transport Research Centre in that period was 309,240. In The Netherlands, blood sampling after a traffic accident only takes place in cases of a suspicion of alcohol use, where an alcohol breath test cannot be performed or in cases of drug use. Therefore, the number of collected blood samples of crash-involved drivers is relatively small. Of the blood samples of crash-involved drivers, 993 (74\%) could unambiguously be linked to the accident records. Single car accidents as well as accidents involving more cars were included. No data were available about the culpability of the driver getting involved in the accident.

\subsection{Outcome}

The primary outcome of the study was the severity of the accident. The accident data used in this study classified the severity of the accident as property damage only, nonserious injury, hospital admission or fatality. An accident was considered to be severe in cases of injury with admission to the hospital or death.

\subsection{Determinants}

The primary determinant of interest was recent use of alcohol, illicit drugs and/or medicinal drugs affecting driving performance. All 993 blood samples were screened for the presence of alcohol, illicit drugs and psychoactive medicines by the NFI.

The group of illicit drugs included opiates, amphetamines, cocaine and metabolites, methadone and cannabinoids. Medicinal drugs affecting driving performance included benzodiazepines, barbiturates and tricyclic antidepressants. Since blood sampling took place to determine whether the driver was under the influence of alcohol or drugs, the assumption has been made that no medication was given in the time between the accident and blood sampling.

Generally, alcohol tests are performed at the police office by using an alcohol breath analyser. A blood sample is taken if the driver is not able to finish the breath test properly, if there is a suspicion of drug-use or in cases of severely injured drivers who are taken by ambulance to the hospital. In those cases, the blood sample is collected in a container with sodium fluoride as a preservative by a physician at the police 
office or at the hospital. In this study, blood alcohol concentrations were determined by the NFI by using the enzymatic 'alcohol dehydrogenase' method, after vapour micro-diffusion (Neuteboom et al., 1980). The results of the breath analyses were unknown. For drug screening, blood was used after protein precipitation with acetone.

Screening for opiates and cannabinoids was performed by using Enzyme ImmunoAssay (EIA, COZART Bioscience Ltd., UK; CODA, BIO-RAD, The Netherlands). The EIA analysis threshold value was $10 \mathrm{ng} / \mathrm{ml}$ for opiates and cannabinoids. Screening for other substances and metabolites was performed by HPLC-UV diode array detection (Waters, The Netherlands) after solid phase extraction (OASIS HLB, Waters, The Netherlands).

\subsection{Data analysis}

Logistic regression analysis was used to evaluate the relationship between drug use and severity of the traffic accident. The strength of the association between drug use and the severity were expressed as OR with $95 \%$ confidence intervals $(95 \% \mathrm{CI})$. In all the comparisons, the reference group consisted of those drivers that were negative for any drug and had a blood alcohol concentration lower than $0.5 \mathrm{mg} / \mathrm{ml}$. Possible confounding factors studied were age, gender, time of the day, day of the week and urban area.

SPSS 11.5 was used for the analysis.

\section{Results}

\subsection{Circumstances of the traffic accident}

The 993 traffic accidents included in this study were spread over the 25 different regions $(40 \pm 19$, range 12-79). Sixty percent of the crashes took place in the urban area. Of the blood samples, $63 \%$ was collected on Friday, Saturday or Sunday.

Of the severe accidents, $63 \%$ occurred from 22:00 to $10: 00 \mathrm{~h}, 66 \%$ took place on the weekend and $53 \%$ in the urban area.

Of the accidents considered not severe, $51 \%$ occurred from 22:00 to $10: 00$ h, $58 \%$ took place on Friday, Saturday or Sunday and $68 \%$ in the urban area.

Table 1 shows the characteristics of the studied population. The mean age of the drivers was 35 (range 15-90) years. Female drivers represented $9 \%$ of the group.

\subsection{Illicit drugs and medicines}

Opiates were found in $4 \%(42 / 993)$ of the samples, amphetamines in 3\% (31/993), cocaine in 7\% (65/993), cannabinoids in $17 \%(168 / 993)$ and methadone in less than $1 \%$ (4/993). Concerning medicinal drugs, benzodiazepines were found in $10 \%$ (102/993), barbiturates in 1\% (6/993) and tricyclic antidepressants in less than $1 \%$ (2/993).
Table 1

Characteristics of the studied population $(n=993)$

\begin{tabular}{|c|c|c|c|}
\hline Characteristic & $\begin{array}{l}\text { Total, } \\
n(\%)\end{array}$ & $\begin{array}{l}\text { Not severe, } \\
n(\%)\end{array}$ & $\begin{array}{l}\text { Severe, } \\
n(\%)\end{array}$ \\
\hline \multicolumn{4}{|l|}{ The driver } \\
\hline Age (mean \pm S.D.) & $\begin{array}{l}35 \pm 13 \\
\text { years }\end{array}$ & & \\
\hline \multicolumn{4}{|l|}{ Gender } \\
\hline Male & $904(91)$ & $392(88)$ & $512(93)$ \\
\hline Female & $85(9)$ & $50(11)$ & $35(6)$ \\
\hline Unknown & $4(<1)$ & $2(<1)$ & $2(<1)$ \\
\hline \multicolumn{4}{|l|}{ Circumstances } \\
\hline \multicolumn{4}{|l|}{ Time of the day } \\
\hline 10:00-22:00 h & $417(42)$ & $216(49)$ & $201(37)$ \\
\hline $22: 00-10: 00 \mathrm{~h}$ & $575(58)$ & $227(51)$ & $348(63)$ \\
\hline \multicolumn{4}{|l|}{ Day of the week } \\
\hline Weekday & $370(37)$ & $186(42)$ & $184(34)$ \\
\hline $\begin{array}{l}\text { Weekend (Friday, } \\
\text { Saturday, Sunday) }\end{array}$ & $622(63)$ & $258(58)$ & $364(66)$ \\
\hline \multicolumn{4}{|l|}{ Road } \\
\hline Urban area & $593(60)$ & $304(68)$ & $289(53)$ \\
\hline Main road/freeway & $400(40)$ & $140(32)$ & $260(47)$ \\
\hline
\end{tabular}

In this study, the age of users of illicit drugs ranged from 15 to 74 years. The age of users of benzodiazepines, tricyclic antidepressants or barbiturates ranged from 17 to 76 years.

Remarkable is the minimum age of some drugged-drivers, considering the legal minimum age to drive a motorbike of 16 years and the minimum age to get a driver's licence of 18 years.

\subsection{Drugs and alcohol}

Fig. 1 shows the percentage of drug-positive cases versus the blood alcohol concentration. Included are the 962 cases analysed for alcohol as well as for drugs.

The percentage of drug-positive cases was $41 \%(66 / 160)$ for the group with a blood alcohol concentration less than $0.5 \mathrm{mg} / \mathrm{ml}$. For the other cases with blood alcohol concentrations of $0.5-0.8,0.8-1.3 \mathrm{mg} / \mathrm{ml}$ and more than $1.3 \mathrm{mg} / \mathrm{ml}$, the percentage cases with additional illicit and medicinal drug use were 35\% (29/82), 35\% (71/205) and 30\% (155/515), respectively.

In $83 \%$ (802/962) of the cases, the blood alcohol concentration exceeded the legal limit of $0.5 \mathrm{mg} / \mathrm{ml}$. The median blood alcohol concentration was about $1.5 \mathrm{mg} / \mathrm{ml}$.

In $34 \%(337 / 993)$ of the blood samples, at least one drug was detected.

Concerning the percentage of the cases with additional use of drugs, the percentage of drug-positive cases seems to decrease with the increasing blood alcohol concentrations.

\subsection{Alcohol and drug use in relation to the severity of the traffic accident}

Table 2 shows the association between alcohol and drug use and the severity of a traffic accident. 


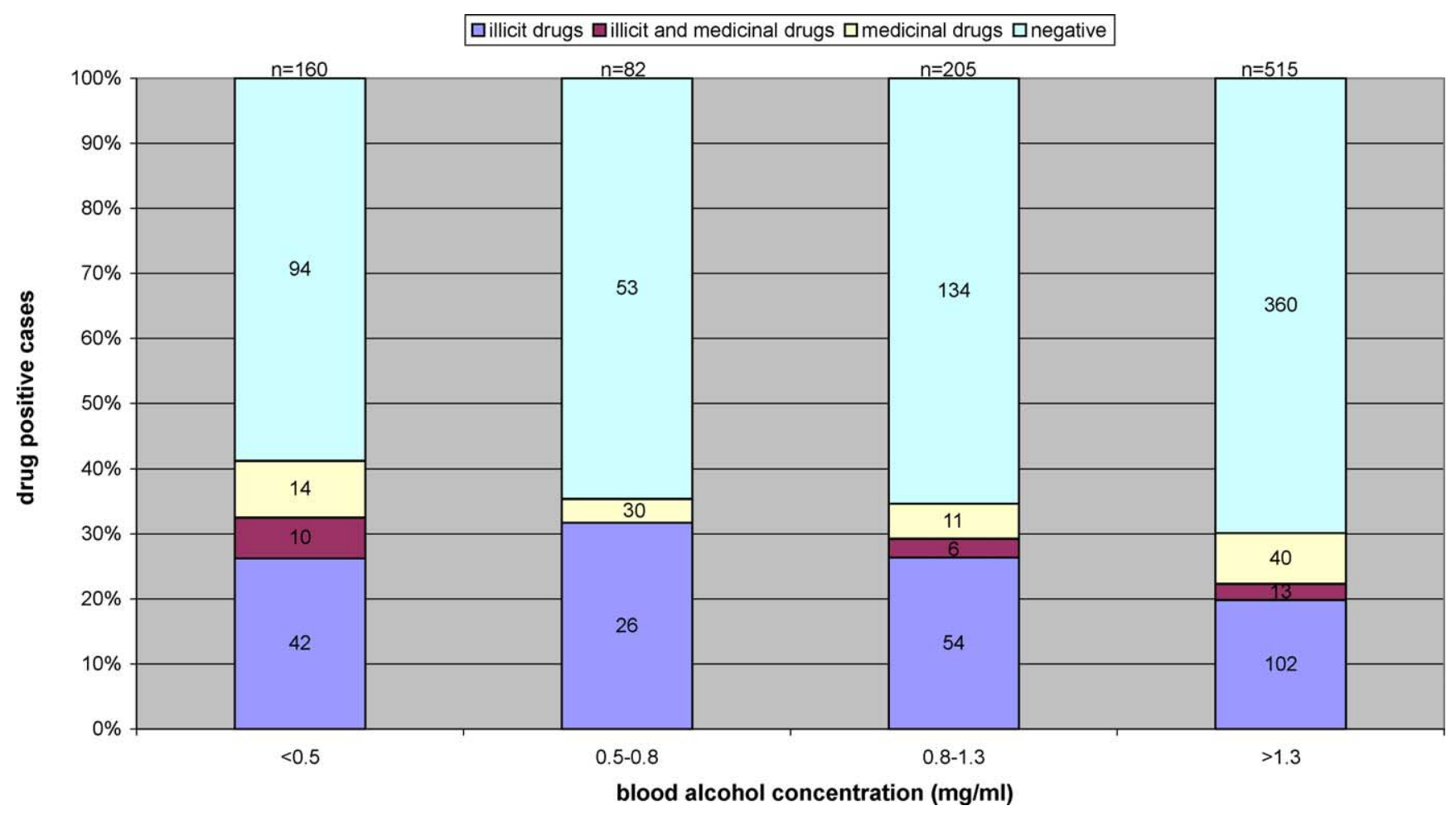

Fig. 1. Percentage of drug-positive cases vs. blood alcohol concentration.

Table 2

Relation between alcohol and/or drug use and the severity of an accident

\begin{tabular}{|c|c|c|c|c|c|c|c|}
\hline & & $\begin{array}{l}\text { Number of } \\
\text { positive cases } \\
n(\%)\end{array}$ & $\begin{array}{l}\text { Not severe } \\
n(\%)\end{array}$ & $\begin{array}{l}\text { Severe } \\
n(\%)\end{array}$ & OR $(95 \% \mathrm{CI})$ & $\begin{array}{l}\text { OR }(95 \% \mathrm{CI}) \\
\text { Adj. for age } \\
\text { and gender }\end{array}$ & $\begin{array}{l}\text { OR }(95 \% \text { CI }) \\
\text { Adj. for age, gender, } \\
\text { time of the day, day of } \\
\text { the week, urban road }\end{array}$ \\
\hline \multicolumn{8}{|c|}{ Alcohol in $\mathrm{mg} / \mathrm{ml}$ (no other drug use) } \\
\hline & $<0.5$ & $94(15)$ & $32(11)$ & $62(17)$ & $1^{*}$ & $1^{*}$ & $1^{*}$ \\
\hline & $0.5-0.8$ & $53(8)$ & $20(7)$ & $33(9)$ & $0.8(0.4-1.7)$ & $0.7(0.4-1.5)$ & $0.5(0.3-1.1)$ \\
\hline & $0.8-1.3$ & $134(21)$ & $51(18)$ & $83(23)$ & $0.8(0.5-1.4)$ & $0.8(0.5-1.5)$ & $0.7(0.4-1.3)$ \\
\hline & $>1.3$ & $360(56)$ & $179(64)$ & $181(51)$ & $0.5(0.3-0.8)$ & $0.6(0.4-1.0)$ & $0.5(0.3-0.9)$ \\
\hline Opiates & & $42(31)$ & $10(24)$ & $32(34)$ & $1.6(0.7-3.8)$ & $1.8(0.8-4.2)$ & $1.6(0.7-3.9)$ \\
\hline Cannabinoids & & $168(64)$ & $71(69)$ & $97(61)$ & $0.7(0.4-1.2)$ & $0.7(0.4-1.2)$ & $0.7(0.4-1.2)$ \\
\hline Cocaine & & $65(41)$ & $36(53)$ & $29(32)$ & $0.4(0.2-0.8)$ & $0.4(0.2-0.8)$ & $0.4(0.2-0.7)$ \\
\hline $\begin{array}{l}\text { Amphetamine and } \\
\text { amphetamine-like } \\
\text { substances }\end{array}$ & & $31(25)$ & $17(35)$ & $14(18)$ & $0.4(0.2-1.0)$ & $0.4(0.2-0.8)$ & $0.3(0.1-0.7)$ \\
\hline Benzodiazepines & & $102(52)$ & $64(67)$ & $38(38)$ & $0.3(0.2-0.6)$ & $0.4(0.2-0.6)$ & $0.4(0.2-0.7)$ \\
\hline \multicolumn{8}{|l|}{ Methadone } \\
\hline Barbiturates & & $6(6)$ & $1(<1)$ & $5(<1)$ & $2.6(0.3-23.0)$ & $3.0(0.3-29.2)$ & $2.6(0.2-26.4)$ \\
\hline \multicolumn{8}{|c|}{$\begin{array}{l}\text { Tricyclic } \\
\text { antidepressants }\end{array}$} \\
\hline \multicolumn{8}{|c|}{ Single vs. multi-drug use $(\mathrm{BAC}<0.5)$} \\
\hline & No drug use & $94(59)$ & $32(54)$ & $62(61)$ & $1^{*}$ & $1^{*}$ & $1^{*}$ \\
\hline & Single drug use & $48(30)$ & $15(26)$ & $33(33)$ & $1.1(0.5-2.4)$ & $1.2(0.6-2.5)$ & $1.1(0.5-2.5)$ \\
\hline & Multi drug use & $18(11)$ & $12(20)$ & $6(6)$ & $0.2(0.1-0.8)$ & $0.2(0.1-0.7)$ & $0.2(0.1-0.7)$ \\
\hline Any drug & & $337(78)$ & $159(83)$ & $178(74)$ & $0.6(0.4-0.9)$ & $0.6(0.4-1.0)$ & $0.6(0.4-1.0)$ \\
\hline Alcohol and drugs & & $255(73)$ & $123(79)$ & $132(68)$ & $0.6(0.3-0.9)$ & $0.6(0.4-1.0)$ & $0.6(0.3-1.0)$ \\
\hline
\end{tabular}

${ }^{*}$ Reference category. In all comparisons, the reference group consisted of those drivers that were negative for any drug and had a blood alcohol concentration lower than $0.5 \mathrm{mg} / \mathrm{ml}$. 
Our results show no association between the blood alcohol concentration and severity of the accident. The OR for blood alcohol concentrations over $1.3 \mathrm{mg} / \mathrm{ml}$ (adjusted OR 0.5 (95\% CI: 0.3-0.9)) seems to support the belief that alcohol may protect against severity of the injury.

The results of opiates (adjusted OR 1.6 (CI 95\%: 0.7-3.9)), cannabinoids (adjusted OR 0.7 (CI 95\%: 0.4-1.2)) or barbiturates (adjusted OR 2.6 (CI 95\%: 0.2-26.4)) indicate that the drug use is not associated with the degree of severity.

The OR for cocaine (adjusted OR 0.4 (CI 95\%: 0.2-0.7)), amphetamines (adjusted OR 0.3 (CI 95\%: 0.1-0.7)) and benzodiazepines (adjusted OR 0.4 (CI 95\%: 0.2-0.7)) may even be in contrast with the expected negative influence of drug use on the severity of the accident.

Given a crash, multi-drug use (adjusted OR 0.2 (CI 95\%: $0.1-0.7)$ ) tends to be associated with a less severe accident compared to single drug use (adjusted OR 1.1 (CI 95\%: 0.5-2.5)). Our results show no association between drug use in combination with alcohol and the severity of a crash.

\section{Discussion}

Given a crash, the use of alcohol or drugs shows no clear association with the severity of the accident. Although it has clearly been shown that alcohol and drug use increase the risk of accidents (Barbone et al., 1998; Borkenstein et al., 1974; Honkanen et al., 1980; Hurst et al., 1994; Marquet etal., 1998; Neutel, 1998; Movig et al., 2004), our data show no relation between the use of alcohol, opiates, cannabinoids, cocaine, ampethamines and benzodiazepines and crash severity. Due to the small number of positive cases for methadone, barbiturates and tricyclic antidepressants, no conclusion can be drawn for those classes of drugs.

Odds ratios were calculated for the different classes of drugs. In most drug-positive cases, we saw poly drug use and/or drug use in combination with alcohol. The number of single drug users with a blood alcohol concentration lower than $0.5 \mathrm{mg} / \mathrm{ml}$ was small. For opiates, the number of single drug-positive cases was 3 , for cannabinoids 17 , for cocaine 12, for amphetamines 4 and for benzodiazepines 12 . Consequently, the OR for the different classes of drugs (in Table 2) may be biased by poly drug use or the combination with alcohol. The finding that the use of some classes of drugs tend to reduce the odds of crash severity is consistent with the reduced OR for multi-drug use (adjusted OR 0.2 (CI 95\%: 0.1-0.7)). The lower odds might be related to the altered mood of the driver, the awareness of driving under the influence or muscle relaxant effects in case of benzodiazepines. However, this has to be proven through further studies.

The most frequently detected drugs were cannabinoids, benzodiazepines and cocaine.

The incidence of driving under the influence of cannabis is rising (O'Kane et al., 2002). In our study, the age of drug users ranged from 15 to 90 years. Marijuana may be used for medicinal purposes by elderly, for example as antiemetic and for the treatment of pain (Grotenhermen, 2003). The use of opiates by young as well as elderly people may be explained by the use of heroin as illicit drug in vivo rapidly hydrolyzed to morphine as well as the use of morphine as analgesic. Codeine, a related opioid agonist, may be present in blood samples of drivers after the use of heroin or after the use of codeine as antitussive. The age of users of benzodiazepines ranged from 17 to 76 years, which in combination with the large number of benzodiazepine-positive cases illustrates the extensive use and probably misuse of benzodiazepines and justifies the concern about the use of benzodiazepines in relation to road safety (Skurtveit et al., 2002).

The effects of alcohol use on the crash severity are controversial (Li et al., 1997). The selection of the study population may be an important factor. Studies not indicating an association between alcohol and outcome included mostly patients admitted to a hospital or traumacenter, while studies suggesting that alcohol adversely affects the outcome mostly are based on data from emergency departments and police departments. Other influencing factors may be, for example time course, outcome measurements and acute versus chronic effects (Li et al., 1997). The retrospective study of Porter (2000) indicates no significant differences in mortality between alcohol positive and negative patients treated at trauma centers, but there was a trend to decreased injury severity in the presence of alcohol. However, no adjustments have been made for confounding variables such as severity of the traumatic events which could have influenced outcome measurements. Other studies conclude that alcohol increases injury (e.g., Kim etal., 1995; Waller et al., 1986, 1997, 2003). Our results are in agreement with those studies where alcohol is not associated with serious crashes and greater injury.

For drugs, most of the existing literature examines the effect on crash involvement. To our knowledge, no data are available to prove the association between different classes of illicit and medicinal drugs and the severity of a traffic accident. Our data are in agreement with other studies where, in the absence of alcohol, drug use in general was not associated with more severe crashes or greater injury (Kim etal., 1995). Stoduto et al. (1993) found no significant differences between the blood alcohol concentration and/or other drug use on injury severity measures. In addition, our data indicate no increased crash severity with the combined use of alcohol and drugs.

Some factors limit the conclusions to be drawn from this study. The major limitation is the potential for selection bias. In The Netherlands, blood sampling by crash-involved drivers is not regulated by law and the sampling protocol is not standard. Thus, not all crash-involved drivers are tested for the use of alcohol and drugs. Blood sampling only takes place in cases of a suspicion of drug-impaired driving (e.g., deviant driving behavior or symptoms of drug use observed during medical examination). As a result, it is likely that the absolute frequencies we found with respect to alcohol or drug use among crash-involved drivers is overestimated due to the 
fact that drug recognition by the police increases the number of drug positive blood tests.

Of more relevance to our research question is whether the blood sampling occurred more or less frequently in drivers involved in more severe accidents, i.e., selection bias. If the frequency of blood sampling would be higher in drivers involved in more severe accidents (e.g., to investigate as much crash characteristics as possible), this would lead to relatively more negative results in severe accidents compared to less severe accidents and thus the odds ratio would artificially decrease. If the frequency of blood sampling would be lower in drivers involved in more severe accidents (e.g., because of practical difficulties in obtaining the sample), this would lead to relatively more positive results in severe accidents compared to less severe accidents and thus the odds ratio would artificially increase. Although the severity of an accident is not a criterion for blood sampling for the Dutch police and the frequency of blood sampling is, therefore, expected to be equal in both the groups, no data are available to confirm this. It is unknown whether blood sampling might be encouraged, for example, by the need of the authorities to clarify all the facts of the case or discouraged, for example, by possible interference with medical assistance.

Another influencing factor might be the difference in time course. Due to medical assistance after a severe accident, time course may be longer between the accident and blood sampling for drug analysis leading to more false negative test results. As a result, the risk estimates will artificially decrease. Unfortunately, it is not possible to make any correction for elimination of the drug in between the accident and blood sampling.

The number of drug negative drivers with a blood alcohol concentration lower than $0.5 \mathrm{mg} / \mathrm{ml}$ was relatively small. According to the Dutch legislation, it is not allowed to take a blood sample of crash-involved drivers without suspicion of alcohol or drug use.

For most effects of medicinal or illicit drugs, concentration-effect relationships exist. A recent study indicates a concentration-related effect of benzodiazepines on impairment in apprehended drivers (Bramness et al., 2002). The severity of a car accident may be influenced by impairment and as a result may depend on the concentration of the drug that is present in the blood. This concentration may drop in the period of time and blood sampling, e.g. when the driver leaves the site of the accident or when the driver is transported to a hospital.

In this study, we did not measure drug concentrations except for alcohol. It is possible that the mere presence of a drug is not a good predictor for the severity of an accident. This would necessitate concentration measurements in future studies. For alcohol, however, we could not demonstrate a relation between the concentration and the severity of an accident.

Severity is measured by material damage and injury to anyone involved in the crash. No data are available concerning the injury level of the driver, total number of passengers involved in the crash, seatbelt use or speed at the time of crash. These data have to be investigated to confirm the finding that some classes of drugs tend to reduce the odds of crash severity, more research has to be done.

Concerning the statistical analysis, data were neither adjusted for characteristics like seat belt use, speed at the time of crash, vehicle weight or signs of fatigue nor for alcohol and/or drug consumption patterns.

Despite the limitations, the results of this study suggest that alcohol and/or drug use is not associated with increased crash severity. Standard blood sampling of all crash-involved drivers is advised to clarify the relation between drug use and the injury severity, given a crash. Blood concentrations should be measured to investigate concentration-effect relationships. This may cover up relationships that could not be demonstrated in this study. Since we cannot entirely rule out that selection bias may have influenced our findings, further confirmation is needed.

\section{Acknowledgments}

This study was supported by a Grant from the Ministry of Transport, Public Works and Water Management, Directorate-General for Passenger Transport (Traffic Safety and Vehicle Directorate) and Directorate-General of Public Works and Water Management (AVV Transport Research Centre).

\section{References}

Barbone, F., McMahon, A.D., Davey, P.G., Morris, A.D., Reid, I.C., McDevitt, D.G., 1998. Association of road-traffic accidents with benzodiazepine use. Lancet 352 (October (9137)), 1331-1336.

Borkenstein, R.F., Crowter, R.P., Zeil, W.W., Zylman, R., 1974. The role of the drinking driver in traffic accidents ("The Grand Rapids Study") Supplement 1. Bloominton, IN. Department of Police Administration, Indiana University. Blutalcohol 11.

Bramness, J.G., Surtveit, S., Morland, J., 2002. Clinical impairment of benzodiazepines-relation between benzodiazepine concentration and impairment in apprehended drivers. Drug Alcohol Depend. 68, 131-141.

Grotenhermen, F., 2003. Pharmacokinetics and pharmacodynamics of cannabinoids. Clin. Pharmacokinet. 42 (4), 327-360.

Harder, S., Reitbrock, S., 1997. Concentration-effect relationship of delta9-tetrahydrocannabinol and prediction of psychotropic effects after smoking marijuana. Int. J. Clin. Pharmacol. Ther. 35, 155-159.

Honkanen, R., Ertama, L., Linnoila, M., et al., 1980. Role of drugs in traffic accidents. Br. Med. J. 281, 1309-1312.

Hurst, P.M., Harte, D., Frith, W., 1994. The grand rapids dip revisited. Accid. Anal. Prev. 26 (5), 647-654.

Ichikawa, M., Nakahara, S., Wakai, S., 2002. Mortality of front-seat occupants attributable to unbelted rear-seat passengers in car crashes. The Lancet 359 (9300), 43-44.

Kim, K., Lawrence, N., Richardson, J., Li, L., 1995. Personal and behavioral predictors of automobile crash and injury severity. Accid. Anal. Prev. 27 (4), 469-481.

Kim, S., Kim, K., 2003. Personal, temporal and spatial characteristics of seriously injured crash-involved seat belt non-users in Hawaii. Accid. Anal. Prev. 35 (January (1)), 121-130. 
Li, G., Keyl, P.M., Smith, G.S., Baker, S.P., 1997. Alcohol and injury severity: reappraisal of the continuing controversy. J. Trauma 42 (March (3)), 562-569.

Marquet, P., Delpla, P.A., Kerguelen, S., Bremond, J., Facy, F., Garnier, M., Guery, B., Lhermitte, M., Mathe, D., Pelissier, A.L., Renaudeau, C., Vest, P., Seguela, J.P., 1998. Prevalence of drug abuse in urine of drivers involved in road accidents in France: a collaborative study. J. Forensic Sci. 43, 806-811.

Movig, K.L.L., Mathijssen, M.P.M., Nagel, P.H.A., van Egmond, T., de Gier, J.J., Leufkens, H.G.M., Egberts, A.C.G., 2004. Psychoactive substance use and the risk of motor vehicle accidents. Accid. Anal. Prev. 36, 631-636.

Neuteboom, W., Logtenberg, H., Verschuren, W., Brouwer, P.W. S, 1980. A new device for automation of the alcohol analysis performed by means of the ADH-method, Proceedings of the Eighth International Conference on Alcohol Drugs and Traffic Safety, Stockholm, Sweden, June $15-19$.

Neutel, C.I., 1998. Benzodiazepine-related traffic accidents in young and elderly drivers. Hum. Psychopharmacol. 13 (Suppl. 2), S115-S123.

O'Kane, C.J., Tutt, D.C., Bauer, L.A., 2002. Cannabis and driving: a new perspective, review article. Emerg. Med. 4, 296-303.

Porter, R.S., 2000. Alcohol and injury in adolescents. Pediatr. Emerg. Care 16 (October (5)), 316-320.
Robertson, M.D., Drummer, O.H., 1994. Responsibility analysis: a methodology to study the effects of drugs in driving. Accid. Anal. Prev. 26 (2), 243-247.

Skurtveit, S., Abotnes, B., Christophersen, A.S., 2002. Drugged drivers in Norway with benzodiazepine detections. Forensic Sci. Int. 125, $75-82$.

Stoduto, G., Vingilis, E., Kapur, B.M., Sheu, W.J., McLellan, B.A., Liban, C.B., 1993. Alcohol and drug use among motor vehicle collision victims admitted to a regional trauma unit: demographic, injury, and crash characteristics. Accid. Anal. Prev. 25 (August (4)), 411420.

Valent, F., Schiava, F., Savonitto, C., Gallo, T., Brusaferro, S., Barbone, F., 2002. Risk factors for fatal road traffic accidents in Udine, Italy. Accid. Anal. Prev. 34 (January (1)), 71-84.

Waller, P.F., Blow, F.C., Maio, R.F., Singer, K., Hill, E.M., Schaefer, N., 1997. Crash characteristics and injuries of victims impaired by alcohol versus illicit drugs. Accid. Anal. Prev. 29 (6), 817-827.

Waller, P.F., Stewart, J.R., Hansen, A.R., Stuuts, J.C., Popkin, C.L., Rodgman, E.A., 1986. The potentiating effects of alcohol on driver injury. JAMA 256 (September (11)), 1461-1466.

Waller, P.F., Hill, E.M., Maio, R.F., Blow, F.C., 2003. Alcohol effects on motor vehicle crash injury. Alcohol Clin. Exp. Res. 27 (April (4)), 695-703. 